\title{
Primary Tooth Extraction Pattern Among Turkish Children with Severe Early Childhood Caries Treated Under General Anesthesia
}

\author{
Merve Candan ${ }^{1}(\mathbb{0}$, Burak Buldur1(1)
}

${ }^{1}$ Department of Pediatric Dentistry, Faculty of Dentistry, Cumhuriyet University, Sivas, Turkey.

Author to whom correspondence should be addressed: Associate Professor Burak Buldur, Department of Pediatric Dentistry, Faculty of Dentistry, Sivas Cumhuriyet University Kampus, 58140 Sivas, Turkey. Phone: +90 346 2191010. Email: bbuldur@gmail.com.

Academic Editors: Alessandro Leite Cavalcanti and Wilton Wilney Nascimento Padilha

Received: 08 November 2019 / Accepted: 12 January 2020 / Published: 20 January 2020

How to cite this article: Candan M, Buldur B. Primary tooth extraction pattern among Turkish children with severe early childhood caries treated under general anesthesia. Pesqui Bras Odontopediatria Clín Integr. 2020; $20:$ e5382. https://doi.org/10.1590/pboci.2020.030

\begin{abstract}
Objective: To determine the frequency and distribution of extracted primary teeth due to severe Early Childhood Caries (ECC) in young pediatric patients treated under general anesthesia. Material and Methods: This study employed a retrospective design and consisted of a total of 1644 children (1011 boys, 633 girls) children aged 3 to 5 who had been diagnosed with several ECC and treated under general anesthesia in a dental faculty between 2013-2019. The data was obtained from the medical and dental forms obtained from the faculty database. The patients were divided according to age groups and sex. A total of 2605 teeth were classified according to the sex, tooth number, and age groups. Results: Of the subjects, $14 \%(\mathrm{n}=245)$ were 3 years old, $31 \%(\mathrm{n}=505)$ were 4 years old, $55 \%(\mathrm{n}=894)$ were 5 years old. The mean $\pm \mathrm{SD}$ age of subjects was $4.2 \pm 0.8 \mathrm{yr}$. While the most extracted teeth were found to be maxillary primary central incisors and molar teeth, the less were found to be mandibular primary canines. While there was a statistically significant difference between canines and incisors with molars $(\mathrm{p}<0.05)$, no difference existed between incisors and molars. There was a statistically significance difference among all age groups $(\mathrm{p}<0.05)$. While 3 years old group had the less number of extracted teeth, 5 years old group had the most number of extracted teeth. Conclusion: Severe ECC causes higher tooth extraction in patients treated under general anesthesia. Effective personal and community programs should be initiated to prevent ECC and mitigate its potential disruptive impacts in children's oral health.
\end{abstract}

Keywords: Child; Dental Caries; Tooth, Deciduous; Anesthesia, General. 


\section{Introduction}

Dental caries is one of the most common chronic diseases worldwide, triggered by genetic, behavioral, environmental and microbial factors [1,2]. Early Childhood Caries (ECC) is defined as the presence of one or more decayed, lost or filled tooth surfaces in any tooth in a child aged 71 months or younger [2]. Severe ECC is defined as the number of tooth decay, missing or filled tooth surfaces at least 4 years old at 4 years old, at least 5 years old at 4 years old, and at least 6 years old at 5 years old [3].

The prevalence of ECC also varies greatly with various factors such as race, culture and ethnicity $[3,4]$. In addition, socioeconomic status, lifestyle, cariogenic diet and inadequate oral hygiene, long-term or faulty bottle use, low birth weight and vertical transition of streptococcus mutans from mother to child, general health status of the child, family income and education level of the mother are among the individual risk factors [5-10]. Although the prevalence rate of ECC is between 1 and $12 \%$ in most developed countries, it is as high as $70 \%$ among less developed and disadvantaged groups in developed countries [9,11].

Severe ECC causes pain, infection, abscess, chewing difficulty, malnutrition, and gastrointestinal disturbances, thus impairing the patient's quality of life due to oral health [3, 12]. Pain caused by tooth decay adversely affects children's ability to learn or perform emotional states, sleep patterns and normal activities [13]. Malnutrition due to physical growth retardation can be seen [14]. However, dental anxiety can be caused by dental treatments at a very early age [15]. Due to premature milk teeth lost due to ECC, incorrect language repulsion, malocclusion and even speech disorders may occur [16]. Multiple treatment sessions may disrupt the child's attendance and performance, and may also affect their parents' work efficiency [17]. In addition, children may get a negative attitudes towards dentistry since they have tough dental procedures $[18]$.

Young children with severe ECC can often be treated with pharmacological behavior guidance techniques because they show cooperation problems. However, radical treatments such as tooth extraction are generally preferred under general anesthesia. Determining the distribution of the extracted primary teeth according to various variables such as sex, age and jaw location in children treated under general anesthesia and having severe ECC is very important both in the development of protective strategies effectively and in consideration of the factors that cause it. Therefore, this study aimed to determine the frequency and distribution of extracted primary teeth due to severe ECC in young pediatric patients treated under general anesthesia. The null hypothesis tested is that there is no difference between the distributions of extracted primary teeth due to severe ECC in pediatric patients treated under general anesthesia.

\section{Material and Methods}

Study Sample

This study employed a retrospective design and was conducted in the Department of Pediatric Dentistry, Sivas Cumhuriyet University between January 2013 - June 2018. The study sample consisted of children aged 3 to 5 who had been diagnosed with several ECC and treated under general anesthesia. The data was obtained from the medical and dental forms obtained from faculty database. Inclusion criteria were as follows: children who were diagnosed with severe ECC between 3-5 years old and had at least one tooth extraction. The teeth that were indicated for extraction and failed despite treatment were included. A total of 1644 children (1011 boys, 633 girls) who met the study criteria were included in the study. The patients were divided according to age groups and sex. A total of 2605 teeth were classified according to the sex, tooth number, and age groups of the children. 


\section{Statistical Analysis}

Statistical analyses were carried out using SPSS 22.0 software (SPSS, Chicago, IL, USA). Descriptive analysis was used to summarize the demographic characteristics of the study sample. The distribution of extracted tooth according to tested independent variables was analyzed by the Chi-square test at 0.05 significance level.

\section{Ethical Aspects}

The study was conducted in accordance with the ethical standards specified in the Helsinki Declaration of 1964 and its subsequent amendments.

\section{Results}

Among all subjects, $61 \%(\mathrm{n}=1011)$ were males and 39\% $(\mathrm{n}=633)$ were females. Of the subjects, $14 \%$ $(\mathrm{n}=245)$ were 3 years old, $31 \%(\mathrm{n}=505)$ were 4 years old, $55 \%(\mathrm{n}=894)$ were 5 years old. The mean \pm SD age of subjects was $4.2 \pm 0.8 \mathrm{yr}$.

Figure 1 shows the distribution of extracted primary teeth according to tooth number and age. While the most extracted teeth were found to be maxillary primary central incisors and molar teeth, the less were found to be mandibular primary canines. Figure 2 shows the distribution of extracted primary teeth according to sex and age. There was no difference regarding sex $(\mathrm{p}>0.05)$.

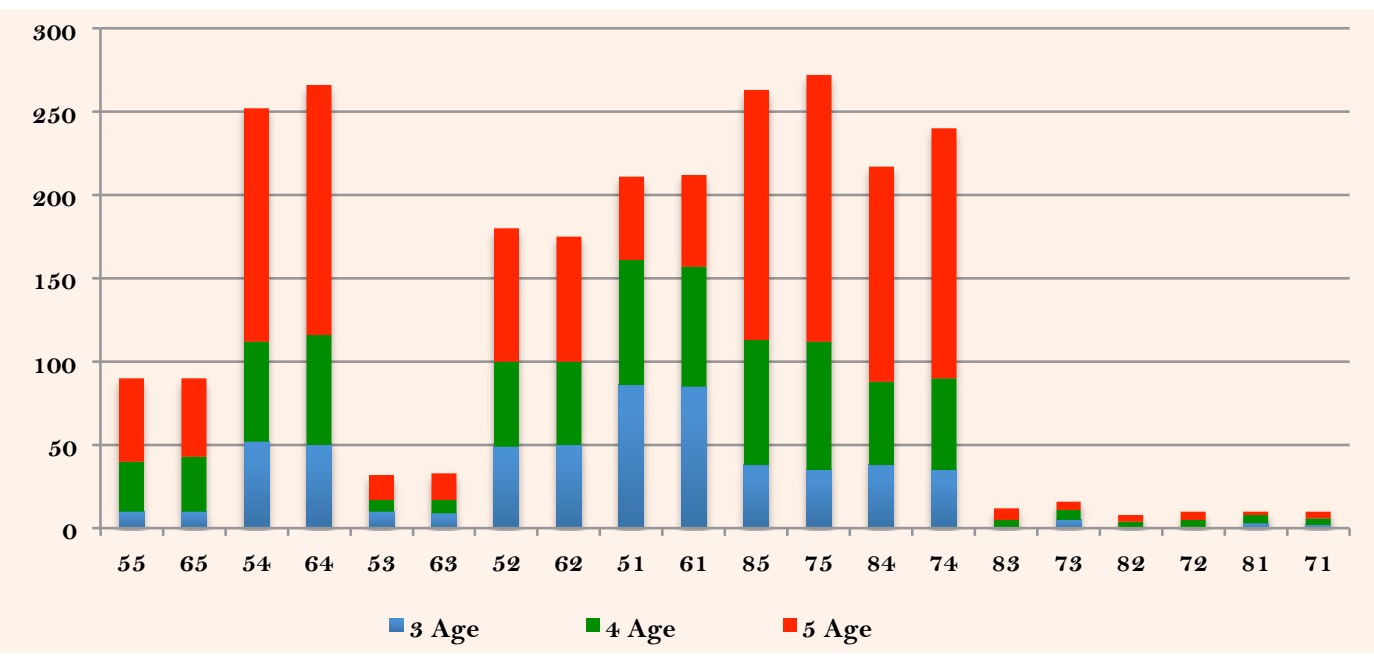

Figure 1. Distribution of extracted primary teeth according to tooth number and age.

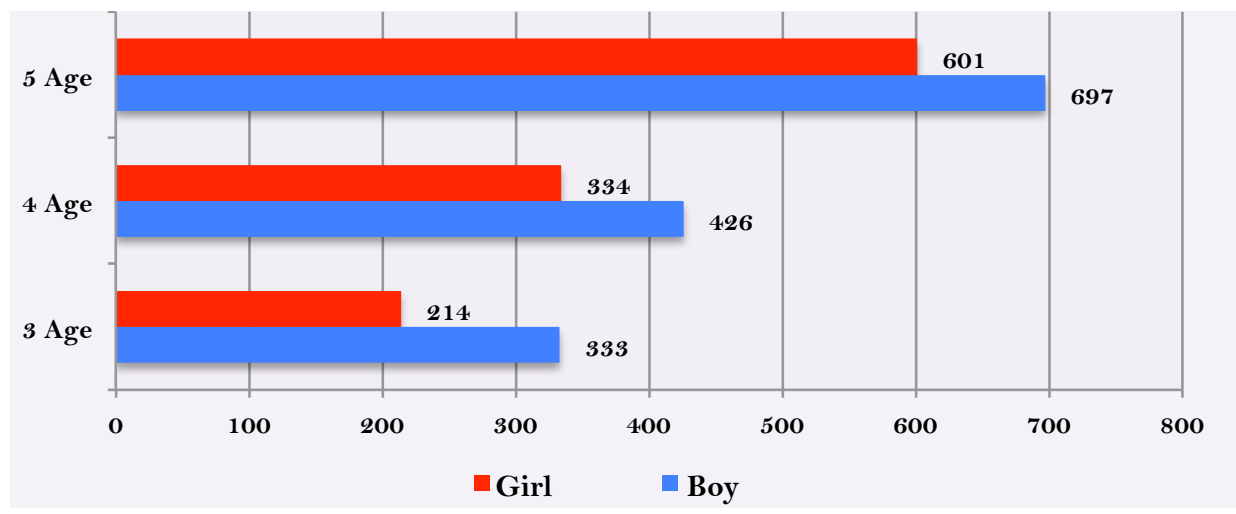

Figure 2. Distribution of extracted primary teeth according to sex and age. 
Table 1 shows the distribution of extracted primary teeth according to tooth type. While there was a statistically significance difference between canines and incisors with molars $(\mathrm{p}<0.05)$, no difference existed between incisors and molars. Regarding incisor teeth, mandibular teeth had significantly more extraction number than mandibular teeth $(\mathrm{p}<0.05)$. In regard with canine and molar teeth, there was no difference between maxilla and mandibula.

Table 1. Distribution of primary teeth extraction according to tooth type.

\begin{tabular}{|c|c|c|c|c|c|c|c|}
\hline \multirow{4}{*}{ Age } & \multicolumn{6}{|c|}{ Tooth Type } & \multirow{4}{*}{$\begin{array}{c}\text { Total } \\
\text { N }\end{array}$} \\
\hline & \multicolumn{2}{|c|}{ Incisor } & \multicolumn{2}{|c|}{ Canine } & \multicolumn{2}{|c|}{ Molar } & \\
\hline & Maxillary & Mandibular & Maxillary & Mandibular & Maxillary & Mandibular & \\
\hline & $\mathrm{N}$ & $\mathrm{N}$ & $\mathrm{N}$ & $\mathrm{N}$ & $\mathrm{N}$ & $\mathrm{N}$ & \\
\hline 3 & 260 & 10 & 19 & 9 & 124 & 125 & 547 \\
\hline 4 & 264 & 18 & 21 & 7 & 184 & 266 & 760 \\
\hline 5 & 271 & 20 & 31 & 12 & 378 & 586 & 1298 \\
\hline Total & 795 & 48 & 71 & 28 & 686 & 977 & 2605 \\
\hline
\end{tabular}

Table 2 shows the distribution of extracted primary teeth according to age groups. There was a statistically significance difference among all age groups $(\mathrm{p}<0.05)$. While 3 years old group had the less number of extracted teeth, 5 years old group had the most number of extracted teeth.

Table 2. Distribution of primary teeth extraction according to localization of jaw.

\begin{tabular}{ccccccccccc} 
Age & \multicolumn{1}{c}{ Right } & \multicolumn{4}{c}{ Maxillary } & \multicolumn{4}{c}{ Left Maxillary } & \multicolumn{2}{c}{ Right Mandibular } & \multicolumn{2}{c}{ Left Mandibular } & Total \\
& N & $\%$ & N & $\%$ & N & $\%$ & N & $\%$ & N \\
\hline 3 & 175 & 37.4 & 43 & 13.3 & 168 & 36.2 & 41 & 12.9 & 427 \\
4 & 198 & 30.0 & 112 & 18.6 & 211 & 31.7 & 186 & 19.6 & 707 \\
5 & 377 & 24.0 & 405 & 25.7 & 373 & 23.8 & 316 & 26.3 & 1471 \\
Total & 750 & 28.0 & 560 & 21.6 & 752 & 28.0 & 543 & 22.2 & 2605 \\
\hline
\end{tabular}

\section{Discussion}

Despite contemporary preventive and treatment approaches in pediatric dentistry, dental diseases are still one of the most common health problems worldwide [1]. Early tooth loss due to dental caries provides insight into the availability of oral health services in the relevant population, as well as common attitudes towards oral health. In order to develop effective methods and protocols for reducing early tooth extraction, it is important to determine the incidence and distribution of early tooth extraction due to caries in children. In addition, extensive dental caries seen at a young age lead to treatment under general anesthesia due to cooperative problems in children [19]. This results in more radical dental treatments preferred by dentists [20] and higher costs [21].

In this hospital-based retrospective study, dental records of pediatric patients with severe ECC between the ages of 3-5 years and treated under general anesthesia were examined. The findings of the study showed that in the patient group with severe ECC and treated under general anesthesia, the maximum tooth extraction was performed in the 5-year-old group, while the molar teeth were the most extracted. However, it was found that the maxillary teeth were found to be more extracted than mandibular teeth. There was no significant difference according to gender.

In the present study, the difference in the age group of extracted teeth is consistent with various studies in the literature [22-26]. Tooth extraction was found to be higher in higher ages. One of the reasons 
for this may be that treatment under general anesthesia is not considered very favorable by the parents and they desire continuous procrastination [27]. In addition, the increased risk of complications due to general anesthesia in small age groups may have resulted to delay dental appointment and in more surgical and dental extraction in the 5-year-old group. Similarly, previous authors reported that more shoots were performed in higher age groups, probably due to differences in the chronology of tooth development [26].

In this study, the most common tooth types were maxillary incisions and first molar teeth. Similarly, some authors reported that primary molar teeth were most commonly extracted [22,26]. This may be due to the anatomic structure of these teeth. The deep pits and cracks on the occlusal surface and the proximal surface of the molars are more prone to caries due to their smooth surfaces [28]. Another reason may be due to the chronological age difference between the two molar tooth types. Furthermore, the success rate of pulp treatment for the primary first molar is generally considered to be low, while the second primary molar is generally maintained preferentially to preserve the area.

Maxillary central incisors are the most commonly extracted teeth in the study group, similar to previous studies [22,29]. Factors such as prolonged breastfeeding, increased sugar intake, delays in the initiation of tooth brushing lead to tooth decay. In addition, it has been reported that the highest incidence of trauma in the first dentist occurred at the age of $2-3$ when the child learned to walk and improve coordination $[30]$.

This study had several limitations. Since the sample selected in the study is from a single hospital, this may prevent the generalization of the study data. In addition, because the data were obtained from hospital records, the diagnosis of severe ECC was made by different dentists who were not calibrated.

\section{Conclusion}

This study highlights the high prevalence of primary tooth extraction under general anesthesia due to severe ECC in a Turkish pediatric population. The findings revealed that severe ECC causes higher tooth extraction in patients treated under general anesthesia. Effective personal and community programs should be initiated to prevent ECC and mitigate its potential disruptive impacts in children's oral health.

\section{Authors' Contributions}

MC D 0000-0002-9839-871X $\begin{aligned} & \text { Conceptualization, Methodology, Investigation, Writing - Original Draft } \\ & \text { Preparation, and Writing-Review and Editing. } \\ & \text { BB } \quad \text { Doooo-0003-4764-819X } \begin{array}{l}\text { Conceptualization, Methodology, Formal Analysis, Writing - Original Draft } \\ \text { Preparation, and Writing - Review and Editing. }\end{array}\end{aligned}$
$\begin{aligned} & \text { All authors declare that they contributed to critical review of intellectual content and approval of the final version to be } \\ & \text { published. }\end{aligned}$

\section{Financial Support}

None.

\section{Conflict of Interest}

The authors declare no conflicts of interest.

\section{Acknowledgments}

The authors would like to thank to Gökhan Aldım for his assistance during data collection process. 


\section{References}

[1] Frencken JE, Sharma P, Stenhouse L, Green D, Laverty D, et al. Global epidemiology of dental caries and severe periodontitis - a comprehensive review. J Clin Periodontol 2017; 44(Suppl 18):94-105. https://doi.org/10.1111/jcpe.12677

[2] Pitts N, Baez R, Diaz-Guallory C. Early childhood caries: IAPD Bangkok Declaration. Int J Paediatr Dent 2019; 29(3):384-86. https://doi.org/10.1111/ipd.12490

[3] Tinanoff N, Baez RJ, Diaz Guillory C, Donly KJ, Feldens CA, McGrath C, et al. Early childhood caries epidemiology, aetiology, risk assessment, societal burden, management, education, and policy: Global perspective. Int J Paediatr Dent 2019; 29(3):238-48. https://doi.org/10.1111/ipd.12484

[4] Kupietzky A. Global cooperation: defining early childhood caries. ASDC J Dent Child 2019; 86(2):71.

[5] Corrêa-Faria P, Paixão-Gonçalves S, Ramos-Jorge ML, Paiva SM, Pordeus IA. Developmental enamel defects are associated with early childhood caries: case-control study. Int J Paediatr Dent 2020; 30(1):11-7. https://doi.org/10.1111/ipd.12574

[6] Fauzia RA, Badruddin IA, Setiawati F. Association between early childhood caries and feeding pattern in 3-to 5-yearold children in Grogol Utara, South Jakarta. Pesqui Bras Odontopediatria Clin Integr 2019; 19(1):e5080. https://doi.org/10.4034/PBOCI.2019.191.112

[7] de Melo Cançado N, Chibinski ACR, Pinto MHB, Wambier DS. Caries prevalence in preschool children in a city of southern Brazil according to two diagnostic criteria: dmf-t and ICDAS II. Pesqui Bras Odontopediatria Clin Integr 2019; 19(1):e4666. https://doi.org/10.4034/PBOCI.2019.191.70

[8] Palmer C, Kent Jr R, Loo C, Hughes C, Stutius E, Pradhan N, et al. Diet and caries-associated bacteria in severe early childhood caries. J Dent Res 2010; 89(11):1224-9. https://doi.org/10.1177/0022034510376543

[9] Anil S, Anand PS. Early childhood caries: prevalence, risk factors, and prevention. FPED 2017; $18(5): 157$. https://doi.org/10.3389/fped.2017.00157

[10] Jain M, Namdev R, Bodh M, Dutta S, Singhal P, Kumar A. Social and behavioral determinants for early childhood caries among preschool children in India. J Dent Res Dent Clin Dent Prospects 2015; 9(2):115-20. https://doi.org/10.15171/joddd.2014.023

[11] Ismail AI, Lim S, Sohn W, Willem JM. Determinants of early childhood caries in low-income African American young children. Pediatr Dent 2008; 30(4):289-96.

[12] Buldur B, Guvendi ON. Conceptual modelling of the factors affecting oral health-related quality of life in children: A path analysis. Int J Paediatr Dent 2019; 2019. https://doi.org/10.1111/ipd.12583

[13] Easton JA, Landgraf JM, Casamassimo PS, Wilson S, Ganzberg S. Evaluation of a generic quality of life instrument for early childhood caries-related pain. Community Dent Oral Epidemiol 2008; 36(5):434-40. https://doi.org/10.1111/j.1600-0528.2007.00417.x

[14] Psoter WJ, Reid BC, Katz RV. Malnutrition and dental caries: a review of the literature. Caries Res 2005; 39(6):441-7. https://doi.org/10.1159/000088178

[15] Buldur B, Armfield J. Development of the Turkish version of the Index of Dental Anxiety and Fear (IDAF-4C+): dental anxiety and concomitant factors in pediatric dental patients. J Clin Pediatr Dent 2018; 42(4):279-86. https://doi.org/10.17796/1053-4628-42.4.7

[16] Dolah S, Eusufzai SZ, Alam MK, Ahmad WMAW. Factors influencing oral health-related quality of life among preschool children in District of Kota Bharu, Malaysia: a cross-sectional study. Pesqui Bras Odontopediatria Clin Integr 2020; 20:e5052. https://doi.org/10.1590/pboci.2020.008

[17] Buldur B. Angel or Devil? Dentists and dental students conceptions of pediatric dental patients through metaphor analysis. J Clin Pediatr Dent 2018; 42(2):1 19-24. https://doi.org/10.17796/1053-4628-42.2.7

[18] Buldur B. Behavior management in pediatric dentistry: an overview and interpretation. Pesqui Bras Odontopediatria Clin Integr 2019; 19(1):e4649. https://doi.org/10.4034/PBOCI.2019.191.ed1.

[19] Collado V, Pichot H, Delfosse C, Eschevins C, Nicolas E, Hennequin M. Impact of early childhood caries and its treatment under general anesthesia on orofacial function and quality of life: a prospective comparative study. Med Oral Patol Oral Cir Bucal 2017; 22(3):e333-e41. https://doi.org/10.4317/medoral.21611

[20] Buldur B, Armfield JM. Perceptions of the dental profession: a comparative analysis through scale development. Eur J Oral Sci 2018; 126(1):46-52. https://doi.org/10.1111/eos.12397

[21] Casamassimo PS, Thikkurissy S, Edelstein BL, Maiorini E. Beyond the dmft: the human and economic cost of early childhood caries. J Am Dent Assoc 2009; 140(6):650-57. https://doi.org/10.14219/jada.archive.2009.0250

[22] Samuel SS, Selvaraj DSS, Ebenezer J, Rebekah G, Koshy S. Nature and pattern of primary teeth extractions in a tertiary care hospital setting in South India. Indian J Dent Res 2018; 29(2):186-9. https://doi.org/10.4103/ijdr.IJDR_195_17

[23] Mukhopadhyay S, Roy P. Extraction of primary teeth in children: An observational study. J Craniomaxillofac Surg 2015; 4(1):57-61. https://doi.org/10.4103/2278-9588.151905

[24] Ak G, Sepet E, Pinar A, Aren G, Turan N. Reasons for early loss of primary molars. Oral Health Prev Dent 2005; $3(2): 113-7$. 
[25] Ockell NM, Bågesund M. Reasons for extractions, and treatment preceding caries-related extractions in 3-8 year-old children. Eur Arch Paediatr Dent 2010; 11(3):122-30.

[26] Alsheneifi B, Hughes C. Reasons for dental extractions in children. Pediatr Dent 2001; 23(2):109-12.

[27] Massoni ACLT, Porto É, Dantas LS, Santos PJO, Silva HP. Training, practices and difficulties of dentists in the care of children and adolescents with special needs in the primary health care. Pesqui Bras Odontopediatria Clin Integr 2017; 17(1):e3650. https://doi.org/10.4034/PBOCI.2017.171.51

[28] Ahmed H, Musale P, Alshahawy O, Dummer P. Application of a new system for classifying tooth, root and canal morphology in the primary dentition. Int Endod J 2020; 53(1):27-35. https://doi.org/10.1111/iej.13199

[29] Alamoudi N. The prevalence of crowding, attrition, midline discrepancies and premature tooth loss in the primary dentition of children in Jeddah, Saudi Arabia. J Clin Pediatr Dent 1999; 24(1):53-58.

[30] Flores MT. Traumatic injuries in the primary dentition. Dent Traumatol 2002; 18(6):287-98. https://doi.org/10.1034/j.1600-9657.2002.00153.x 